\title{
Pericardial, pleural, and diaphragmatic endometriosis
}

\author{
Marcello Ceccaroni, MD, PhD, ${ }^{\mathrm{a}, \mathrm{b}}$ Roberto Clarizia, $\mathrm{MD},{ }^{\mathrm{a}, \mathrm{c}}$ and Angelo Placci, $\mathrm{MD}^{\mathrm{d}}$
}

A 28-year-old woman with a clinical history of pelvic endometriosis had catamenial pelvic and abdominal pain with irradiation up to the right shoulder, depending on her breathing or position, as well as impaired motility or sensitivity during the pain peaks. Results of the physical examination and electrocardiogram were within normal limits. Echocardiography revealed no cardiac abnormalities. She underwent laparoscopy for eradication of pelvic and bowel endometriosis. During the procedure, a wide diaphragmatic endometriosis was diagnosed. The right and left diaphragmatic peritoneum was completely infiltrated by confluent nodules, as was the diaphragmatic pericardial insertion. By median xifo-umbilical incision, a wide resection of the left and right diaphragm and left and right parietal basal pleura was done. A resection of more than $4 \mathrm{~cm}$ of parietal pericardium (at the level of its insertion on the central tendon), with opening of a pericardial window, was also performed, thus sparing the left phrenic nerve fibers (nerve-sparing wide diaphragmatic resection). One and 3 months later, the woman experienced no pelvic and/or thoracic pain at all (Figures 1 and 2).

From the Gynecologic Oncology Division, ${ }^{\text {a }}$ International School of Surgical Anatomy, Sacred Heart Hospital, Negrar, Verona, Italy; the Department of Obstetrics and Gynecology, ${ }^{\mathrm{b}}$ European Gynaecology Endoscopy School, Sacred Heart Hospital, Negrar, Verona, Italy; the Department of Obstetrics and Gynecological Sciences, ${ }^{\text {c }}$ University of Naples "Federico II," Naples, Italy; and the Department of Cardiology, ${ }^{\mathrm{d}}$ Santa Maria delle Croci Hospital, Ravenna, Italy.

Disclosures: None.

Received for publication July 18, 2010; accepted for publication July 26, 2010.

Address for reprints: Marcello Ceccaroni, MD, PhD, 37024 Negrar, Verona, Italy

(E-mail: roberto.clarizia@gmail.com).

J Thorac Cardiovasc Surg 2010;140:1189-90

$0022-5223 / \$ 36.00$

Copyright (c) 2010 by The American Association for Thoracic Surgery

doi:10.1016/j.jtcvs.2010.07.064 


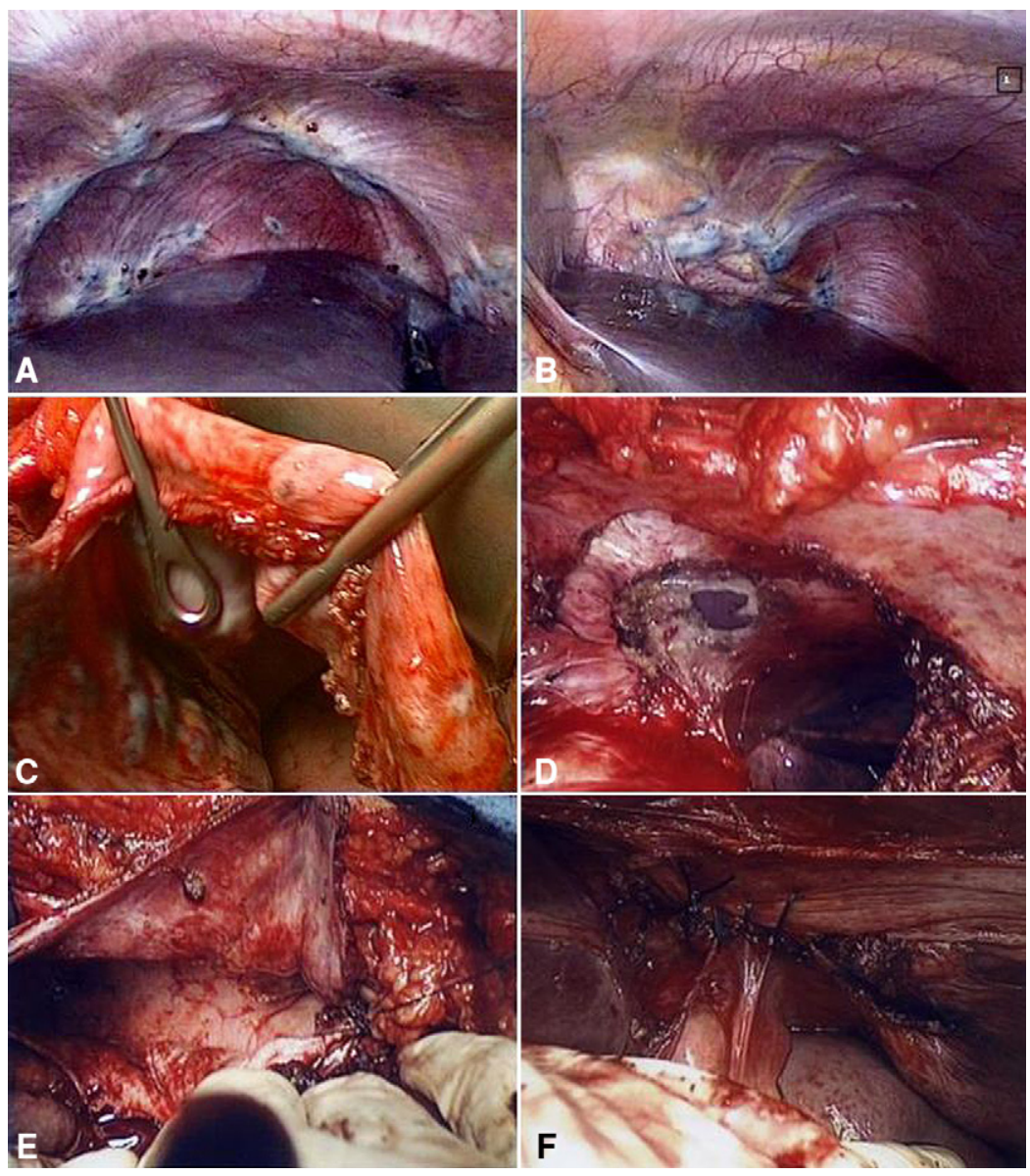

FIGURE 1. Right (A) and left (B) diaphragmatic peritoneum completely infiltrated by confluent nodules, from 0.5 to $5 \mathrm{~cm}$, reaching and involving the central tendon of the diaphragm, near the upper hepatic veins and on the diaphragmatic pericardial insertion. Right (C) and left (D) wide diaphragmatic resection, with opening of the pleural and pericardial cavity, revealing multiple parietal full-thickness infiltrating nodules involving the parietal pleura and diaphragmatic central tendon and infiltrating the diaphragmatic side of the pericardium. Right pleural and diaphragmatic suture (E) and left pleural and diaphragmatic suture with pericardial window closure (F) by a single layer (1-0 polypropylene) suture. Owing to the elasticity, optimal compliance, and good surgical mobilization of the patient's diaphragm, we chose not to fulfill the diaphragmatic gap by an artificial mesh to avoid further complications in case of rectal leakage and peritonitis.

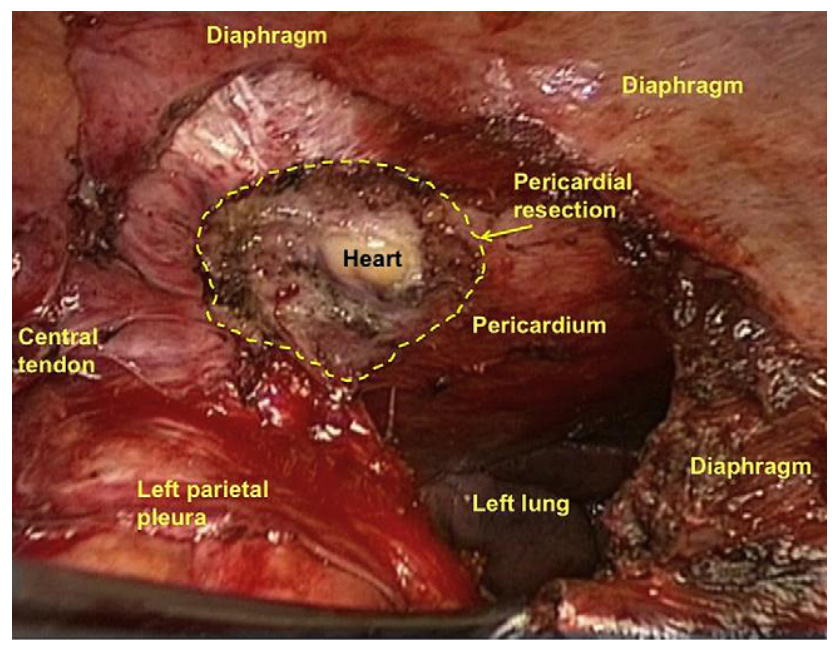

FIGURE 2. Anatomic description of the surgical field after wide resection of left diaphragmatic vault, left parietal pleura, and pericardial resection for infiltrating endometriosis. 